\title{
THE ORIGIN OF THE FORMATION OF LARYNGEAL CYSTS
}

\author{
(EPIGLOTTIC CYSTS)
}

Ryo Takahashi \& Yoshio Honda

The cyst on lingual surface of epiglottis is most trequently discovered under the laryngeal cysts. The reports on the origin of the formation of epiglottic cyst have been published by Juras, Chiari, Senator, Kahler, Louys, Glas. Oppikofer, and Senator etc. since W. Grüber (1875) had maken a study of it's cyst: But generally, the results to be assented are not existent. It is impossible to agree with the explanation, which is congenital because pharynx and larynx in embryonic process happen complicated changes or cysts appear too much on lingual surface of epiglottis.

But congenital cysts are appered rarely, authors consider that the epigiottic cysts in new born are truely congenital cysts. But the wall of cyst in new born has an unusual tissue (cartilage or bone) in hystological findings, this fact is the difference with those of adult.

In addition, epiglottic cysts are seen scarcely in child and school boy, and they are showed almost since puberty, especially in adult; rarely in new born and scarcely in child and school boy.

According to such a difference in hystological observation and a gap of the age, it is concidered that there is some difference on the origin of the cysts in adult and new born.

Authors investigated a origin of the formation of epiglottic cysts in adult. In proportion to become adult, lingual tonsil in pharyngeal lymphoid tissue tenders to suffer from chronic inflammtion. Then it is much frequency that epiglottis is exposed in same condition too. This chronic inflammation becomes a serious proximate cause to formation of epiglottic cysts.

Since several years, we have investigated particular hystology of human epiglottis. In consequence we could discover the interesting observations on epiglottic glands of human. Sixty-six cases were observated, and in 12 cases the cystic enlargement or retention of excretory duct were found.

Most cysts were found on the lingual surface of epiglottis, and the others were on the lingual ground and laryngeal surface.

Epiglottis is covered by mucus membrane (stratified squomous epithel at lingual surface and ciliated epithel at laryngeal surface), and cartilage lies in the centre of it. Then, between epithel and cartilage, there is tunica propria that is mede from conective tissue, including gland, lymphoid tissue and blood vessels.

Then epiglottis is divided into lingual and laryngeal surface with cartilage. Every small

$$
61-61
$$


masses of glands were scattered in crevices of cartilage. The excretory duct of the glands were opened almost on the mucus membrane of laryngeal surface; all glands consisted in the laryngeal surface open on the laryngeal surface, and the majority of glands in the lingual surface open on laryngeal surface too. Although such a matter had been described in Zucker-Kandl's anatomy, we have observated the more interesting matter, as follows.

Very few ducts open on the lingual surface, therefor the opening part on the mucus membrane of the lingual surface is to be found by careful research. The opening parts of ducts exist almost near the radix of the epiglottis.

Tracing the course of this duct from opening part to centre, man will be able to find the duct runs along submucus tissue and reaches into the transitional part of epiglottis and lingual ground.

That is, the gland existing in the transitional part does no: open directly on the near mucus membrane and the duct runs up submucus of the lingual surface and opens on the difinite part of the lingual surface. 'Therefor the couse of duct is long. (Fig. 1-3)

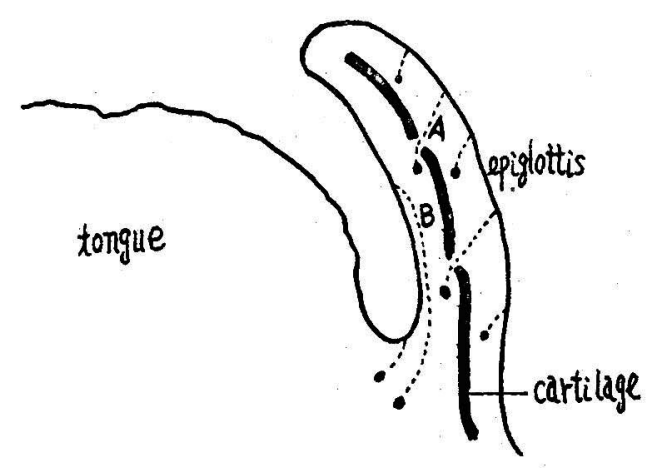

Fig. 1, Process of duct of epiglottis (dotted line)

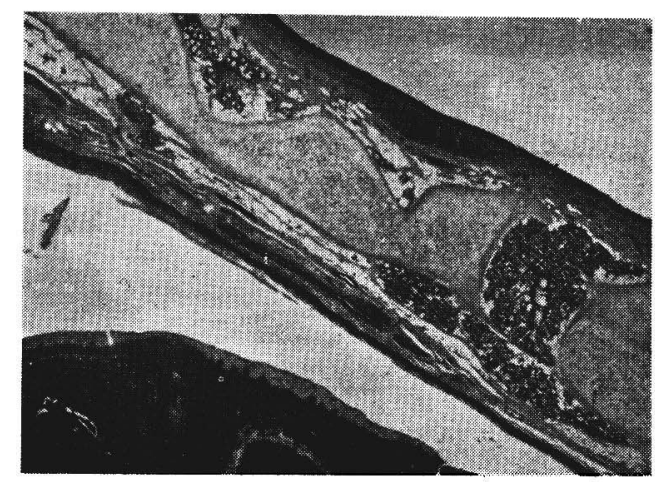

Fig. 3, duct of lingual surface (B. of Fig. 1)

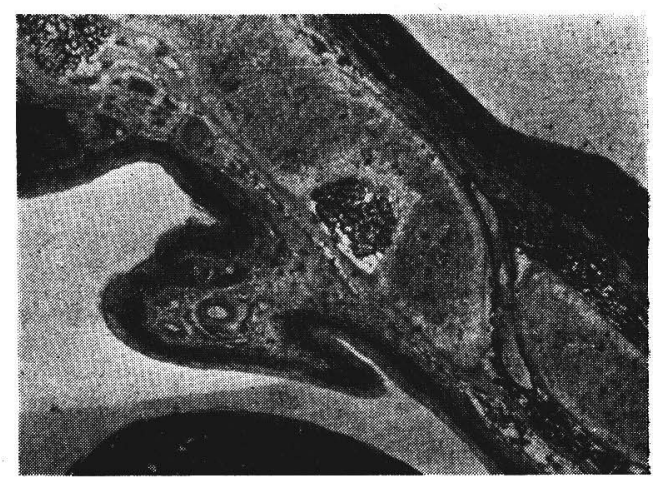

Fig. 2, Duct running to the laryngeal surface through the crevice of cartilage (A. of Fig. 1)

From the first, the cysts on the lingual surface of epiglottis like to appear on the radix of epiglottis and the transitional part. This voluntary appearing part of cysts coincides completely with the course of the gland, which opens on the lingual surface.

Already as descrived, there are frequently chronic inflammation in mucus membrane of epiglottic valeculla of adult. Then, this long duct is influenced easly by the inflammation of mucus membrane 
and tends to be strictured, at last gets to be retention cyst.

Because the opening part of the duct were surrounded with lymphoid tissue, easily should become to be strictured.

Therefor epiglottic cysts are divided into three classes as follows, (Fig. 4-6)

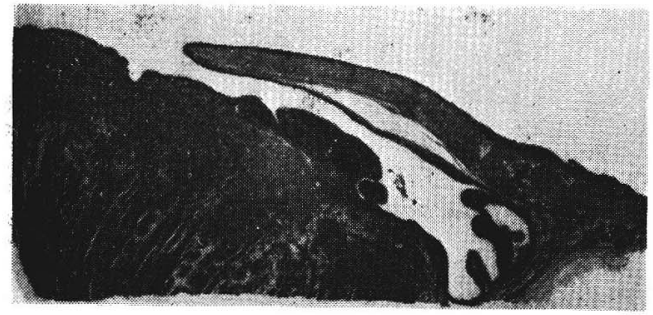

Fig. 4, Cyst on opening part of duct

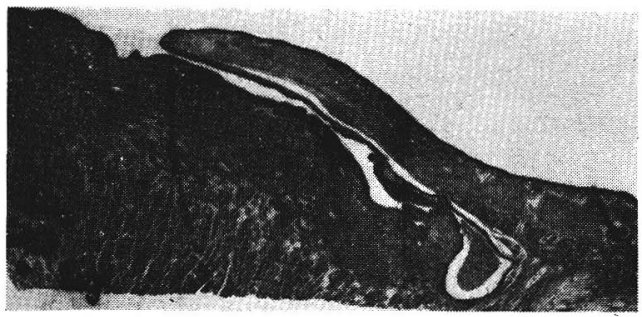

Fig. 5, Ductal cyst

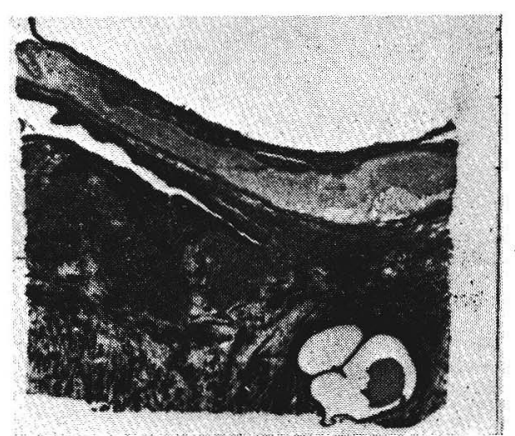

Fig. 6, cyst of gland

(1) cysts on the opening part of duct,

(2) ductal cysts,

(3) cysts of gland.

From olden times, for the purpose of investigating the origin of the formation of epiglottic cysts, internal epithel of cyst, surrounding tissue (lymphoid tissue, gland etc.) and the fact that cyst is divided with septum or not, have been discussed. But those factors would be settled easily, if think about the above mentioned three cases. Cyst on the opening part is covered with stratified squomous epithel and surrounded with lymphoid tissue. Ductal cyst may be covered with various forma! epithel. Glandular cyst happens frequently at transitional part of epiglottis and lingual ground, and is divided by septum. But because the epithel tends to change, the origin of formation is don't researched with it only.

\section{Histological Investigation of Oesophagitis Oedematosa Circumscripta Chronica}

* Shoji Niho M. D.

Kazuhide Yasuda M. D.

In 1951, a lesion which should be referred to as Oesophagitis Oedematosa Circmscripta Chronica was presented by the authors. The chief complaint of patients with this lesion is foreign-body sensation at the upper part of the oesophagus. Although there are many

* Yokohama Kyoyu-Kai 